УДК 81'373+81'373.43 + 81'374

ББК 81

\section{Ли Ли}

\section{БЕСТИАРИЙ РУССКОГО ЯЗЫКА: ПУТИ ЗАПОЛНЕНИЯ ЛАКУН В ОБОЗНАЧЕНИИ САМОК И ДЕТЕНЫШЕЙ}

Показана роль бестиария русского языка в национальной языковой картине мира как постоянно расширяющего свои границы пласта лексики. Бестиарий представлен тремя группами - базовыми парадигмами (полными, неполными и незаполненными). В полных парадигмах особый интерес представляют супплетивные образования. Для этой группы отмечена тенденция к выравниванию парадигмы путем создания мотивированных неодериватов. В неполных парадигмах, представленных двумя разновидностями, также активно идут процессы расширения за счет дифференциации по полу или обозначения детеныша.

Ключевые слова: нащиональная языковая картина, бестиарий, зоологизм, неологизм, неодериват, Викисловарь, неформальная интернет-коммуникаиия.

DOI 10.18522/1995-0640-2020-3-93-102

Ли Ли - аспирант кафедры русского языка для иностранных учащихся Института филологии, журналистики и межкультурной коммуникации Южного федерального университета

Тел.: +7-918-584-77-57

E-mail: 251154108@qq.com

(C) Ли Ли, 2020.
В понятие бестиарий мы включаем названия животных (самцов, самок, детенышей) в широком понимании этого термина: «В научном смысле к животным, помимо млекопитающих, пресмыкающихся и земноводных, относится огромное множество других организмов: рыбы, птицы, насекомые, паукообразные, моллюски, морские звёзды, черви и другие» [Википедия].

Объектом нашего исследования послужили производные от названий животных - названия самок и детенышей - как уже освоенные языком, так и новые слова (неологизмы и неодериваты). К неологизмам мы относим новые слова, зафиксированные в словарях новых слов, новейших толковых словарях, в Викисловаре. Под неодериватами понимаем новые слова, функционирующие в неформальной интернет-коммуникации, появляющиеся как результат рефлексии интернет-пользователей, как продукт языковой игры.

Вершиной национальной картины мира, безусловно, является человек, в материальной жизнедеятельности его особая роль отводится живой природе, которая, по восприятию человека, «существует вокруг него» и «для него» [Пятаева, 2018, с. 62].

В свою очередь, важной составляющей этого фрагмента картины является зоолексика, зоологизмы: «Коммуникативная важность группы обусловливается тем, что её элементы и их производные заметно расширяют возможности речевого осуществления мыслительных конструктов, ко- 
торые принято называть интенциями, или смысловыми намерениями» [Чжэн Икуй, 2001].

Эти смысловые намерения находят выражение с помощью словообразования, так как первой функцией словообразования является функция «ословливания и означивания мира» [Кубрякова, 2004, с. 407].

Бестиарий русского языка является упорядоченной системой деривационных отношений, но наличие в этой системе лакун, заполнение которых происходит как в стандарте, так и в субстандарте, придает нашему исследованию актуальность.

Учитывая, что в русском языке производные слова входят в ядро бестиария (а синтетические названия с родовыми понятиями самка и детеныш находятся на периферии), для обозначения групп зоологизмов мы будем использовать понятие парадигмы, конкретизируя ее следующим образом: базовые полные парадигмы, куда входят названия самца, самки и детеныша, базовые неполные, которые образуют названия взрослого животного и детеныша или самца и самки, и незаполненные - название взрослого животного. Уточним также, что понятие базовая введено как подчеркивающее понимание бестиальной парадигмы как многомерной структуры, куда могут входить и другие производные, имеющие отношение к классу животных.

В данном исследовании мы ограничимся анализом полных и неполных парадигм.

Рассмотрим их в предложенном порядке.

Предваряя анализ выделенных нами групп, рассмотрим ряд важных для нашего исследования положений. Наличие общности в человеческом и животном мире отображается в определенной симметричности языковых категорий:

а) для обозначения самок животных используются те же суффиксы (но не в полном наборе), что и для обозначения лиц женского пола (так называемые суффиксы женскости): -их(a), -иц(a), -к(a), -ин(я)/-ын(я).

Подтип существительных с суффиксом -ux(a), обозначающих самку животного, названного мотивирующим существительным, характеризуется как продуктивный [Лопатин, Улуханов, 2016, с. 411]. Существительные на -им(a) имеют ограниченную продуктивность: ср. «эпизодич. прод. в худож. речи» [Там же, с. 420]. Ограниченную продуктивность проявляют и существительные на -к(a) [Там же, с. 466]. Производные на -ин(я)/-ын(я) представлены в словаре нейтральным гусыня и разговорным догиня. Тип характеризуется как «эпизодич. прод. в разг. речи» [Там же, с. 388];

б) для обозначения детенышей животных используется тот же суффикс, что и для обозначения невзрослых лиц: -онок/-ёнок Этот тип обладает высокой продуктивностью [Там же, с. 601].

В то же время образование названий детенышей с этим суффиксом имеет свою специфику: «В существительных со значением невзрослости различие по полу нейтрализовано в названиях детенышей животных 
(зайчонок - детеныш любого пола; ср. поваренок - ребенок мужского пола)» [Улуханов, 2005, с. 163].

Названия детенышей образуются также с помощью суффикса -ныш/-ёныш. Этот суффикс сочетается только с названиями животных. Тип продуктивен в разговорной и художественной речи [Там же, с. 605].

Анализ материала, представленного в «Сводном словаре современной русской лексики», словарями-источниками для которого послужили 14 словарей, позволяет выявить следующую картину объединений животных:

I. Полные базовые парадигмы.

I. 1. Группа, в которой названия самца и самки составляют привативную оппозицию с маркированной формой женского рода (верблюд верблюдица, воробей - воробьиха).

Данные словарей-источников позволяют говорить о том, что таких парадигм насчитывается свыше 40. Прежде всего, это названия домашних животных, что вполне закономерно, напр.: коза - козел - козленок, индюк - индюшка - индюшонок и др. Далее следуют названия диких животных, напр.: бобер (бобр) - бобриха - бобренок, заям - зайчиха зайчонок и др. Часто подобные парадигмы образуют названия птиц, напр.: воробей - воробьиха - воробъенок, глухарь - глухарка - глухаре нок и др. В этой группе можно увидеть название пресмыкающихся, ср.: змей - змея - змеенок, змееныш. Интерес представляют и ракообразные: рак - рачиха - рачонок.

В полной парадигме маркированным может выступать и название самца, напр.: коза - козел - козленок.

Данные словообразовательного анализа подтверждают приведенные ранее сведения о продуктивности/непродуктивности суффиксов, используемых для названий самок.

Самым продуктивным для обозначения самок оказывается суффикс -их (a), ср.: волчиха, ворониха и др. Продуктивность суффикса -их (a) при обозначении самок животных подтверждается данными как узуального, так и окказионального словообразования, что и будет показано далее.

Считаем также необходимым отметить такое явление, как дублетность, напр.: волчиха, волчища; зубриха, зубрища; лиса, лисица; медведиха, медведица; перепелка, перепелица; тетерка, тетеря; тигра, тигрица.

При обозначении детенышей животных явно лидирует суффикс -онок/-ёнок, слова с суффиксом -оныш/-ёныш единичны: гусеныш, змееныш. Оба они имеют дублеты, но если в случае с гусенок- гусеныш обе лексемы отмечены в большинстве словарей-источников, то змеенок, в отличие от змееныш, представлен только в БАС.

Как показал словообразовательный анализ, мотивирующим выступает название самца, даже если маркированной является форма муж-

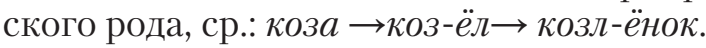

Примером формирования новой полной парадигмы может служить одновременное появление двух неологизмов: китенок и китиха [Словарь новых слов русского языка, 1995, с. 292 - 293]. 
1.2. Несомненный интерес в этой группе зоологизмов представляют супплетивные образования: баран - овща - ягненок; бык - корова -теленок; конь - лошадь - жеребенок; пес - собака - щенок; петух - курица цыплленок.

Все приведенные супплетивные пары названий взрослых животных обладают высокой частотностью, при этом «женский коррелят либо превосходит по частотности мужской, либо незначительно ему уступает» [Улуханов, 2005, с. 64], ср.: лошадь (126), корова (75) - бык (68), овиа (33) - баран (8), курища (26) - петух (18).

Такая же картина наблюдается и при обозначении детенышей: «Почти все наиболее частотные названия детенышей - это немотивированные слова, хотя и имеющие суфф. -онок. <..>. Это названия детенышей всех основных домашних животных, имеющихся в крестьянском хозяйстве: лошадь - жеребенок (частотность 5), свинья - поросенок (частотность 6), корова - теленок (частотность 9), собака - щенок (частотность 8), курища - иыпленок (частотность 12), овиа - ягненок (частотность 12)» [Там же, с. 65].

В то же время эта группа явно является «слабым» звеном в зоолексике, так как для последней характерна мотивированность. Подобные явления, будучи әнтропийными, имеют тенденцию к замене на более «сильные» варианты [Пятаева, 2018, с. 132].

Во-первых, это неодериваты - названия самок, напр.: поросиха, щььплиха [Стела Цейтлин, http].

Во-вторых, это названия детенышей:

Как правильно назвать детеныша овиы?

Часто можно встретить такие названия:

овчик;

ребенок овиы;

овчёнок;

бараненок;

маленькая овечка;

овченыш и т.д [https://mnogo-krolikov.ru/ovcy/kak-nazyvayutrebenka-ovechki-i-barana-yagnenok-ili-ovchenok.html]. Обратим внимание на комментарий: часто можно встретить такие названия.

Как видим, здесь представлены производные и от названия самца, и от названия самки

Т.А. Гридина приводит еще один вариант наименования детеныша в детской речи: «Овечка овёнка родила [Гридина, 2007, с. 100].

Бык - корова - теленок

В Викисловаре зафиксирована лексема бычонок с пометой разг. и со значением «молодой бык». С таким же значением она приводится и в «Толковом словаре» Ефремовой.

Конь - лошадь - жеребенок

В неформальной интернет-коммуникации неологизм лошаденок обладает высокой частотностью употребления. Там можно увидеть ряд стихотворений с одноименным названием. В одном из них Лошадиха 
(мать Лошаденка) в ответ на призывы называть ее сына Жеребенком возмущенно стучит копытами и настаивает на своем праве называть ее сына Лошаденком:

Пусть я матерь-одиночка, но лошастик - мой ребёнок!

Значит, будет Лошадёнок! [https://www.stihi.ru/2019/12/13/3148]/

Встречается в интернет-коммуникации и неодериват коненок, появляющийся в ходе дискуссии о том, как называть ребенка лошади.

Пес - собака - щенок

Лексема псенок, по всей видимости, приобрела уже узуальный характер, о чем свидетельствует включение ее: а) в Викисловарь, правда, без указания значения и примеров употребления; б) в «Толковый словарь» Ефремовой со значением «щенок» и пометой разг;; в) в «Толковый словарь» Кузнецова с тем же значением.

Аналогичен, видимо, статус и лексемы собачонок. Ее можно увидеть в Викисловаре со значением «щенок собаки» и с пометой разд. и в «Толковом словаре «Ефремовой» с той же пометой и со значениями «Детеныш собаки; щенок».

Петух - курица - цыпленок

Неодериват петушонок можно встретить в языке Интернета для напр. Петух и петушонок [https://www.passionforum.ru/posts/58056petuh-i-petushonok.html].

Лексема куренок зафиксирована в Викисловаре с пометой прост. в значении «птенец курицы; цыпленок».

Л.И.Плотникова, анализируя новые слова с позиций порождения речи, замечает, что если «готовое слово» по каким-то причинам не устраивало говорящего, то «он конструировал сам необходимую единицу, используя известные ему словообразовательные модели» [Плотникова, 2004, c. 287].

II. Неполные базовые парадигмы.

Здесь можно выделить три подгруппы.

1. Название взрослого животного - существительное мужского рода и название детеныша, напр.: аист - аистенок.

2. Название взрослого животного - существительное женского рода и название детеныша, напр.: белка - бельчонок.

3. Название самца и самки, напр.: паук - паучиха.

Обозначение взрослого животного в первой и второй подгруппе по вполне понятным причинам приводится безотносительно к полу, напр.: Аист, -а, м. Крупная перелетная птица с длинным мечевидным клювом и длинными ногами, с белым или черным оперением [MАС, 1981, т. I, с. 27]. Галка, -и, ж. птица сем. вороновых, с темным оперением [Там же, с. 298].

Активные деривационные процессы отмечены в первой и третьей подгруппах. В первой подгруппе образование деривата-названия самки связано с тем, что «в категории мужского рода представление о поле выражено менее определенно, чем в обозначениях лиц женского рода» 
[Виноградов, с. 74; цит. по: Улуханов, 2005, с. 164]. Дериват заполняет существующую лакуну в обозначении родо-половой соотнесенности в мире животных.

В первой подгруппе было выявлено 23 пары, в которые входят взрослое животное - существительное мужского рода и детеныш. Возможность появления в этой группе названия самки была проверена по ряду электронных словарей, прежде всего Викисловарю, «многофункциональному мобильному лексикографическому источнику, предметом описания в котором “являются все лексические единицы, зафиксированные во всех письменных языках и диалектах мира” [https:// ru.wiktionary.org/wiki]. Источником материала послужила также неформальная интернет-коммуникация как возможность поиска заданного слова: «Для дериватологии здесь особенно значимо то обстоятельство, что заданное слово можно смоделировать по актуальным для исследователя свойствам. Тем самым осуществляется возможность проекции «модельных» слов в речевую реальность, перехода от иллюстративного поиска лексических реализаций к системному, от эвристического описания к прогностическому» [Голев, 2010, с. 202].

Результатом поиска в Викисловаре стало появление 8 полных парадигм. Правда, не все лексемы представлены в словаре в полном объеме их лексических, морфологических и других признаков, не все поля оказываются заполненными.

Наиболее полное описание дано таким лексемам, как аистиха, дроздиха. В поле «Значение» читаем: разг. самка аиста - в первом случае, дрозда - во втором. Приводятся примеры употребления слов.

Любопытно, что в то же время незаполненным в Викисловаре оказалось поле «Значение» для лексемы дрозденок, которая включена в БАС.

Для лексемы грачиха отсутствуют примеры употребления. Это поле не заполнено и для лексемы грачонок, хотя оно входит во все словари русского языка.

Производное от страус - страусиха - приводится в «Толковом словаре» Кузнецова.

Лексемы кротиха, пингвиниха, соболиха, ужиха, шакалиха присутствуют в поле «Родственные слова» для всех мотивирующих слов, но для них в Викисловаре есть только болванки статей. В то же время все эти лексемы активно функционируют в неформальной интернет-коммуникации, что можно увидеть в следующих контекстах:

1 ) Кротиха

\section{Крот и кротиха}

До первого поработав чиха, В гости пришла кротиха [https://www.stihi.ru/2019/12/02/1543].

2) Пингвиниха

Пингвинихи оказывают секс-услуги, но не бесплатно. За свои «услуги» самки требуют оплату... камнями [http://www.zooplandia.ru/ articlelist].
3) Ужиха 


\section{Уж, ужиха и питон}

Ужиха встретила ужа.

Послушай, друг, я Госпожа...[https://www.proza.ru/2014/11/09/168].

4) Шакалиха

Использовано в названии стихотворения - «Шакалиха-мать» [https://www.stihi.ru/2019/03/06/2354].

Исключение составляет только лексема соболиха, так как в языке Интернета активен его омоним - топоним Соболиха.

Рассмотрим коррелятивные пары животных, само существование которых подталкивает к тому, что возможно появление наименования детеныша.

Это такие пары, как: енот - енотка, изюбр - изюбрица, паук - паучиха, сохач - coхатиха.

Енот - енотка

Первая из лексем отмечена всеми толковыми словарями русского языка, вторая - только в БАС. В Викисловаре есть две синонимичные лексемы - енотка и образованное по другой, более продуктивной модели - енотиха. Обе снабжены пометой разг.

В языке Интернета нам встретились два производных со значением «детеныш енота», ср.: Когда енотята немного подрастут, интервал между кормлениями увеличится [https://yandex.ru/search/?lr=39\&clid= $1946579 \&$ win $=125 \&$ text].

Второе производное - енотыш - является рефлексией интернетпользователей на обсуждение названий детенышей, ср.:

- Как назвать детеныша енота?

- Eнотыши [https://otvet.mail.ru/question/73615384].

Изюбр (изюбрь) - изюбрица

Здесь наблюдается та же картина. Отметим, что в Викисловаре для лексемы изюбрииа поле «Значение» остается незаполненным, также как и для лексемы изюбренок. В то же время в «Толковом словаре» Ефремовой последняя толкуется как «детеныш изюбра».

Паук - паучиха

Обе лексемы узуальны, но если первая опять-таки зафиксирована всеми толковыми словарями русского языка, то вторая - только в БАС. Название детеныша паука - паучонок - находим в Викисловаре.

Сохатич - сохатиха

Вторая лексема, как и в предыдущих случаях, зафиксирована только в БАС. Производное для обозначения детеныша - сохатенок - послужило названием для книги В.Никонова.

В результате анализа языкового материала мы пришли к следующим выводам: мой.

1. Бестиарий русского языка является живой, движущейся систе-

2. Наиболее продуктивными при создании неологизмов и неодериватов являются суффиксы -их (a) и -онок/-ёнок, что позволяет говорить 
о стабильности словообразовательной системы в плане обозначения животных.

3. Образование неодериватов в семьях супплетивного характера соотношения основ говорит об унификации способов обозначения самок и детенышей, о выравнивании парадигмы.

4. Активность словотворчества в неформальной интернет-коммуникации свидетельствует об интересе пользователей к этому пласту лексики и, в конечном итоге, к важности зоолексики в национальной языковой картине мира.

\section{Литература}

Википедия URL: https://ru.wikipedia.org/wiki (дата обращения 25.02.2020).

Викисловарь. URL: ru.wiktionary.org/wiki (дата обращения: 20.02.2020).

Гридина Т.А. Коновалова Н.И. (2007) Современный русский язык. Словообразование: теория, алгоритмы анализа, тренинг: учеб. пособие. М.: Флинта; Наука. 160 с.

Голев Н.Д. (2009) Поисковые системы Интернета как лингвистический источник (на примере решения некоторых теоретических и прикладных вопросов русского словообразования: система и функционирование) // Новые явления в славянском словообразовании: докл. ХІ Междунар. науч. конф. Комиссии по славянскому словообразованию при Междунар. комитете славистов (М., МГУ им. Ломоносова, 24-26 марта 2009). С. 197 - 201.

Eфремова T. Ф. Толковый словарь русского языка. URL: www.efremova.info (дата обращения: 20.02.2020).

Кубрякова Е.С. (2004) Язык и знание. На пути получения знаний о языке: Части речи с когнитивной точки зрения. Роль языка в познании мира. М.: Языки славянской культуры. 560 с.

Кузнещов С.A. Толковый словарь. URL: https://gufo.me/dict/kuznetsov (дата обращения 21.02.2020).

Лопатин В.В. Улуханов И.С. (2016) Словарь словообразовательных аффиксов современного русского языка. М.: Азбуковник. 812 с.

Плотникова Л.И. (2004) Новое слово с позиций порождения речи // Русский язык: исторические судьбы и современность: II Междунар. конгр. исследователей русского языка (Москва, МГУ им. М.В.Ломоносова, фил. ф-т, 18-21 марта 2004 г.): труды и материалы. М. С. $286-287$.

Плтаева Н.В. (2018) Антропоцентрический и синергетический принципы линвистики в динамическом исследовании лексических гнезд. М.: Флинта. 212 с.

Сводный словарь современной русской лексики (1991): в 2 т. М.: Русский язык. Т.1. 800 с. Т. 2.739 с.

Словарь новых слов русского языка (середина 50-х - середина 80-х годов). (1995). СПб. 878 c.

Словарь русского языка: в 4 т. 2-е изд., испр. и доп. Т. І. (1981) М.: Русский язык. 698 с. (МАC).

Стела Цейтлин. Очерки по словообразованию и формообразованию в детской речи URL:razovaniyu-i-formoobrazovaniyu-v-detskoy-rechi-stella-ceytlin/ $\mathrm{read} / \mathrm{page-1.html} \mathrm{(дата} \mathrm{обращения} \mathrm{05.03.2020).}$

Улуханов И.С. (2005) Мотивация в словообразовательной системе русского языка. М.: Азбуковник. 314 с. 
Чжэн Икуй. (2001) Русские зоонимы в комплексном лингвистическом рассмотрении: дис. ... канд. филол. наук. M. URL: https://www.dissercat.com/ content/russkie-zoonimy-v-kompleksnom-lingvisticheskom-rassmo] (дата обращения 27.02.2020).

\section{References}

Dictionary of new Russian words (mid-50s - mid-80s). (1995) Saint Petersburg. 878 p. (In Russian).

Dictionary of the Russian language (1981): in 4 vols. 2nd ed., ISPR. and add. T. I. Moscow. 698 with (MAS). (In Russian)

Efremova T. F. Explanatory dictionary of the Russian language. URL: www. efremova.info (accessed 20.02.2020). (In Russian).

Golev N.D. (2009) Internet Search engines as a linguistic source (on the example of solving some theoretical and applied issues of Russian word formation: system and functioning). New phenomena in Slavic word formation: The reports of XI Int. scientific Conf. The Commission on Slavic word formation at the International level. Committee of Slavists (Moscow, Lomonosov Moscow state University, March 24-26, 2009). P. 197-201. (In Russian).

Gridina T. A., Konovalova N. I. (2007) Modern Russian language. Word formation: theory, analysis algorithms, training: textbook. manual. Moscow. 160 p. (In Russian).

Kubryakova E. S. (2004) Language and knowledge. On the way to gaining knowledge about language: Parts of speech from a cognitive point of view. The role of language in learning the world. Moscow. 560 p. (In Russian).

Kuznetsov S. A. Url dictionary: https://gufo.me/dict/kuznetsov (accessed 21.02.2020). (In Russian).

Lopatin V. V., Ulukhanov I. S. (2016) Dictionary of word-formation affixes of modern Russian language. Moscow. 812 p. (In Russian).

Plotnikova L. I. (2004) New word from the position of speech generation. Russian language: historical destinies and modernity: II Interd. Congress of researchers of the Russian language (Moscow, Lomonosov Moscow state University, Phil. f-t, March 18-21, 2004): Proceedings and materials of Moscow. P. 286-287. (In Russian).

Pyataeva N. V. (2018) Anthropocentric and synergetic principles of linguistics in the dynamic study of lexical nests. Moscow. 212 p. (In Russian).

Stela Zeitlin. Essays on word formation and form formation in children's speech. URL: razovaniyu-i-formoobrazovaniyu-v-detskoy-rechi-stella-ceytlin/read/page1.html (accessed 05.03.2020). (In Russian).

Summary dictionary of modern Russian vocabulary (1991): In 2 t. Moscow. Vol. 1. 800 p. T. 2. 739 p. (In Russian).

Ulukhanov I. S. (2005) Motivation in word-formation system of the Russian language. Moscow. 314 p. (In Russian).

Wikipedia URL: https://ru.wikipedia.org/wiki (accessed 25.02.2020).

Wiktionary. URL: ru.wiktionary.org/wiki (accessed 20.02.2020).

Zheng Ikui. (2001) Russian zoonyms in complex linguistic consideration: dis. ... PhD in Philology'. Moscow, URL: https://www.dissercat.com/content/russkiezoonimy-v-kompleksnom-lingvisticheskom-rassmo] (accessed 27.02.2020). (In Russian). 
Li Li (Rostov-on-Don, Russian Federation)

Bestiary of the Russian Language: Ways to Fill Gaps in the Designation of Females and Cubs

The role of the bestiary of the Russian language in the national language picture of the world as a constantly expanding layer of vocabulary is shown.

The bestiary is represented by three groups-basic paradigms (complete, incomplete, and unfilled). In complete paradigms, suppletive formations are of particular interest. For this group it is marked a tendency to a leveling of the paradigm by creating a motivated neoderivatives. In incomplete paradigms, represented by two varieties, there are also active processes of expansion due to differentiation by gender or designation of the cub.

Key words: national language picture, bestiary, zoologism, neologism, neoderivative, Wiktionary, informal Internet communication.

Li Li - post-graduate student of the Department of Russian language for foreign students. Southern Federal University. Institute of Philology, Journalism and Cross-Ccultural Communication. Phone: +7-918-584-77-57; e-mail: 251154108@qq.com 